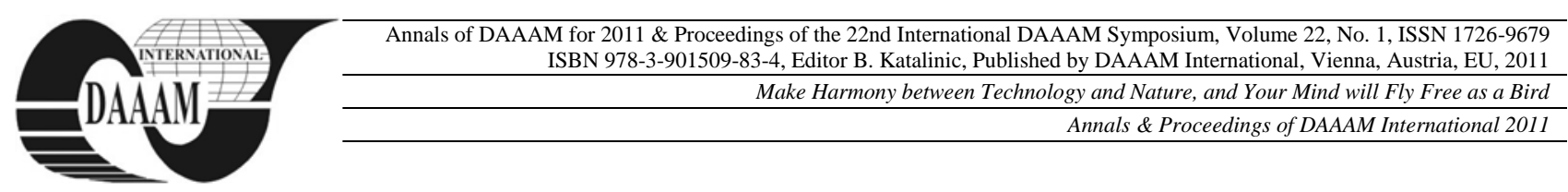

\title{
THE INFLUENCE OF GROUNDING EVENTS ON MARITIME INDUSTRY
}

\author{
VARSAMI, A[nastasia] E[lena]; POPESCU, C[orina]; DUMITRACHE, C[osmin] L[aurentiu]; HANZU - \\ PAZARA, R[adu]; CHIRCOR, M[ihael] \& ACOMI, N[icoleta]
}

\begin{abstract}
In the shipping business ships' grounding have always represented an important topic when talking about accidental loads due especially due to their impact on the marine environment. Taking this into consideration, we must also keep in mind that ship structures include various types of constructions like fast vessels built of front edge technology materials to very large commercial ships built according to traditional procedures. Groundings are considered to be accidental loads and it is clear that the field of ship structures with respect for accidental loads could focus on highly varying topics. The purpose of the present paper is to contribute to the understanding of ship grounding events and how they changed the maritime industry and their major consequences regarding marine environment pollution.
\end{abstract}

Key words: ship, grounding, maritime industry, pollution

\section{INTRODUCTION}

Over the past decades there has been a continuous increase in the public concern about general risk issues. The consequence of this trend is that whenever a catastrophic accident occurs and receives the proper media coverage there is an immediate political and public demand for actions to prevent the same type of catastrophe in the future.

Examples of this pattern are seen in connection with the grounding of the Exxon Valdez and the following requirements for double hulls and in connection with the loss of the Estonia with the following reformulations of requirements for ferry design and operation.

Many of the past improvements in safety of marine structure have been triggered by disasters but there is a change in this trend.

The maritime society is beginning, albeit slowly, to think and work in terms of safety assessment of individual ships instead of the much generalized prescriptive regulations which have evolved over the past 150 years.

In line of these aspects it is clear that rational procedures for evaluating the consequences of accidental loads are highly desirable, not to say necessary.

Accidents like the grounding of Exxon Valdez or Braer or the loss of both Estonia and Titanic demonstrated the potential seriousness and fatality of marine accidental loads.

Yet, although the public, the governmental bodies and the marine society have long recognized the danger of accidental loads, it has been noticed the need for further work.

A fundamental problem with rational consideration of grounding and collision in rules is that there are no simple measures of a ships defense against these loads.

An idea would be to consider the correlation between major design changes and the amount of oil spilled but the amount of oil spilled seems to be a random process and this is the main reason for which it is impossible to draw cause and effect conclusions.

\section{CHANGES IN SHIPS' CONSTRUCTION DUE TO GROUNDINGS}

Accidents like the grounding of Exxon Valdez or Braer or the loss of both Estonia and Titanic demonstrated the potential seriousness and fatality of marine accidental loads. Yet, although the public, the governmental bodies and the marine society have long recognized the danger of accidental loads, statistics demonstrate the need for further work.

A fundamental problem with rational consideration of groundings in rules is that there are no simple measures of a ships defense against these loads. An idea would be to consider the statistical correlation between major design changes and the amount of oil spilled but it has been noticed that the amount of oil spilled seems to be a random process. Within a reasonable time span this makes it impossible to draw cause and effect conclusions from statistics alone and attempts of doing so would most likely be highly reactionary with questionable effectiveness.

There is a methodology which takes into account the high level of uncertainty and randomness of groundings. Inside this methodology there are three steps to take into consideration:

- Hazard identification, meaning what could go wrong and what are the consequences. For example this could be oil spill due to grounding of a tanker in a certain geographic area.

- Scenario identification, meaning what are the steps leading to the hazard and what is the probability of a given hazard.

- Risk assessment from the two analyses above calculates the product of consequence and probability.

As an example, the result of the analysis above could be that the probability of up to 1000 tons of oil spilled along a certain coast line in one year is $10^{-3}$. Now with the risk quantified it would be up to governments, and international regulatory bodies to set up acceptance criteria.

Risks cannot be eliminated but it can be reduced to a level acceptable to society. There are no universally acceptable risks so decision-makers have to identify levels of risk that are tolerable.

\section{WHAT A GROUNDED SHIP MEANS}

\subsection{Definition of a Grounded Ship}

A grounded ship is in a position not intended by her designers, builders, or operators, and is subject to very different forces and conditions than when in normal service. The ship is more like a poorly designed, inadequately protected, and usually inappropriately placed breakwater than a ship at sea. Part of a grounded ship's weight is supported by the surrounding water, part by the ground. The portion of the ship's weight supported by the ground is ground reaction $(R)$, or tons aground; it is equal to the lost buoyancy. The ground reaction 
distribution is uneven and unpredictable. There are four major effects of ground reaction:

- The loss of buoyancy alters hydrostatic characteristics and hull girder loading.

- The upward force of ground reaction at the keel causes a virtual rise in the center of gravity.

- Extremely high local loading with damage or penetration of the hull can occur, particularly on rocky bottoms.

- Ground reaction holds the ship stationary; she cannot respond to or fall away from disturbing forces, such as waves, as she does when afloat.

The conditions of a grounding event are seldom fully defined in the beginning and often are not completely defined during the salvage operation. The grounding condition and the environment are the principal sources of forces on a grounded ship.

Ship's salvage is time-critical because environmental conditions may improve or worsen with time, but the condition of a grounded ship steadily deteriorates.

The way the ship lays on the ground and her position relative to the seafloor and coastline influence the casualty in two ways:

- The way the ship lies on, and is supported by, the ground is a principal indicator of the effort required to free her.

- Distribution of the ship's weight between residual buoyancy and ground reaction affects stability and strength.

The ship's position relative to the shore and underwater features can either intensify or mitigate environmental effects. Specific considerations are:

- Magnitude and distribution of ground reaction.

- Changes in list and trim caused by the stranding.

- The area of the ship in contact with the bottom.

- Depth of water under and around the ship.

- Channel depth - depth of water between the ship and unobstructed deep water.

- Position and attitude of the ship relative to the ground and the shore.

\subsection{Types of Groundings}

An overall view on groundings categorizes the accidents in two major groups:

- Grounding on soft sea beds, so-called Soft Groundings. The damage to the hull in terms of crushing at the point of ground contact is limited but the hull girder may fail in a global mode due to shear force and bending moment exceeding the hull girder capacity.

- Grounding on hard bottoms - so-called Hard Groundings. The primary concern here is the local crushing and tearing of the ship bottom due to a cutting rock.

Together with analysis of the damage which can develop during grounding, it is relevant to consider the residual strength and the stability of the ship in the post-accident condition.

\subsection{Salvage of a Grounded Ship}

Ships are built for a wide variety of purposes, but all must meet certain fundamental requirements. They must have reserve buoyancy to enable them to carry their designed loads and resist damage, stability to resist environmental forces or damage, and strength to withstand the stresses imposed on their structure by their own weight, cargo, stores, and the sea.
There is a basic difference in the way naval architects and salvage engineers approach the problems of ship stability and strength. Naval architects, as designers, divide the subject into examinations of intact and damage conditions. The stability and strength of a proposed design is examined in normal operating, or intact, conditions, which must, as matter of course, include free liquid surfaces in tanks. Damage stability analysis examines a ship design in various hypothetical conditions of damage that include breaches in the immersed hull.

The salvage engineer on the other hand, deals with damaged stability and strength, i.e., ships in conditions of known or identifiable damage that may or may not include breaches in the immersed hull.

There is a subtle distinction between damage and damaged stability. A salvage engineer doesn't really deal with damage stability, or for that matter, with intact stability either. He deals with damaged stability, and conditions that can reasonably be attained from the initial damaged condition. While the salvage engineer also examines hypothetical conditions, those conditions usually have as a point of departure an initial damaged condition.

\section{CONCLUSION}

Ships' groundings can have devastating effects on the marine environment. Cleaning up after a major grounding event could lead to enormous amounts of money and even then there is no certainty that the cleaning process has the best results or even the wanted results.

The society needed these kind of events to truly admit that there is an increased need for safer ships and also for new requirements in ships' construction so that these kind of unfortunate events would not be met again in the future in the maritime business. It is not a good thing that these requirements are triggered only when there is an appropriate media attention given to these events. This kind of requirements should first of all come from the shipbuilders and afterwards from the shipowners but due to the high costs involved that arise from these safety measurements it can be easily understood that it is not in their interest to raise the expenses in the process of building a ship.

Also, when talking about salvaging a grounded ship, it is first of all necessary to fully understand the grounded event that lead the ship into that position so that the best method for salvaging to be applied. It is an important demand to establish the appropriate method of salvaging so that the risk of polluting to be reduced at minimum

\section{REFERENCES}

Barsan, E. \& Muntean, C. (2010). Combined Complex Maritime Simulation Scenarios for Reducing Maritime Accidents Caused by Human Error, Proceedings of the WSEAS 3rd International Conference on Maritime and Naval Science and Engineering, September 3-5, Constanta, ISSN: 1792-4707 88 ISBN: 978-960-474-222-6, pp. 88-93, Published by WSEAS Press, Constanta

Cahill, R. A. (1985). Strandings and their causes. Fairplay Publications, ISBN 0905045602, London

Deboveanu, M. (2002). Tratat de manevra navei, Volume 3, Lumina Lex Publisher, ISBN 973-588-564-6, Bucharest

National Research Council, Committee on Tank Vessel Design (1991). Tanker Spills: Prevention by Design, National Academy of Sciences, National Academy Press, ISBN 9780-309-04377-9, Washington D.C.

Novac, I. \& Chiotoroiu, L. (2004). Teoria navei. Rezistenta la Inaintare a Navelor, Ex Ponto Publishing House, ISBN 973-644-7, Constanta

Simonsen, B. C. (1997). Mechanics of Ship Grounding. Technical University of Denmark, ISBN 87-89502-34-5, Lyngby 